\title{
The parameterization of the demand for machinery as a Dimension-and-Quality function affecting industrial furniture production
}

\author{
Witold Jarecki ${ }^{1}$, Marek Wieruszewski ${ }^{1 *}$, Bartosz Pałubicki ${ }^{2}$, Krzysztof Wiaderek $^{3}$, Eukasz \\ Matwiej $^{3}$, and Dariusz Orlikowski ${ }^{I}$ \\ ${ }^{1}$ Sun Garden Polska Spółka z Ograniczoną Odpowiedzialnością Spółka Komandytowa, \\ ${ }^{2}$ Katedra Obrabiarek i Podstaw Konstrukcji Maszyn, Wydział Leśny i Technologii Drewna, \\ Uniwersytet Przyrodniczy w Poznaniu, \\ ${ }^{3}$ Katedra Meblarstwa, Wydział Leśny i Technologii Drewna, Uniwersytet Przyrodniczy w Poznaniu,
}

\begin{abstract}
Machine processing parameters, including the feed speed and the working speeds of tools, are determined by: the minimum demand for material in a specific branch of the furniture industry, the expected quality, as well as the form and type of wood processed. Due to the considerable diversity of physical and mechanical properties of raw wood there are high demands concerning process and machine individualisation in technology planning. Setting the right processing parameters is necessary to make high-quality semi-finished and finished products. In order to increase the precision of machining specialised tool and transport systems need to be used. At the same time, the increase in the required production efficiency is inversely correlated with the individual characteristics of the raw material and the desired indicators of the quality of products. A harmonised level of these parameters is the main assumption in the selection of machine tools and auxiliary devices. The analyses conducted in this study showed that there are numerous variables in methods of selecting machines and devices for raw wood processing. When selecting machining systems, enterprises should use a system of weights to indicate which elements (quality and dimensions or efficiency) are of primary importance for them.
\end{abstract}

\section{Introduction}

The planning, implementation, efficiency and economic effectiveness of raw material processing as well as the acquisition and production of finished products are basic assumptions for the selection of machinery and devices in the wood industry. The defining of production requirements includes providing information on the number of operations ranging from the acquisition of raw material to its processing so as to meet customers' expectations $[1,2]$. The following basic tasks need to be done in technological solutions in order to meet production requirements $[3,4]$ :

*Corresponding author: mwier1312@wp.pl 
- the demand for the volume of ready-made products for consumers,

- a certain degree of complexity of the construction of end products,

- the demand for the volume of flow of raw materials for production,

- the minimisation of costs of technological processes and material flow [5].

Many authors define the selection of machinery as a sphere of the technological development of the economic activity under study and as a link between technological and economic knowledge. This distinction may be the basis for a more precise definition of the concept of 'machine demand' [6,7]. The limitations commonly cited in scientific publications can be classified according to the basic concepts of influence factors:

- limitations resulting from the processes affecting the flow of material elements - raw materials, materials, semi-finished products, and finished products,

- the organisation of material flows reflecting the shaping and management of technological processes as well as the systems controlling these processes,

- the right concept of managing the quality of processing and materials, based on an integrated, systemic approach to adjusting these parameters to technological processes,

- $\quad$ logistics ensuring the correct flow of materials and information in an enterprise and in its individual links $[8,9]$.

The aforementioned concepts of machine demand planning are consistent and they complement each other.

Material processing in the contemporary wood industry is more and more complicated. In order to support planning the technological demand with decisions it is necessary to provide and process relevant information. The logistic demands of the modern market are more and more challenging. The time of delivery of the product ordered by the customer is becoming shorter and shorter. The course of sales is usually unstable due to fluctuations resulting from competition, the intensity of marketing activities and the lack of information about the place where the demand for products is growing rapidly. This dynamics of market activities complicates logistic procedures, which need to implemented in the shortest time possible. As the prices of software are falling and computer technology is developing more and more rapidly, it is possible to use IT solutions more and more frequently for an effective flow of information in logistic systems [10]. In consequence, there is a constant search for newer and better integrated IT systems enabling efficient management of logistic processes. Currently the market offers various systems supporting the management of enterprises. Therefore, customers need to evaluate them in detail. The use of IT systems increases the transparency of decision-making processes in enterprises. The effective use of IT systems for the management of logistic processes in an enterprise should consist in adapting IT systems to the company rather than the other way round. Moreover, the system should be simple and intuitive not to discourage its users.

Modern machine systems should:

- guarantee sufficient processing efficiency,

- $\quad$ support integrated machining processes - both main and auxiliary,

- enable the change of material and quality processes,

- $\quad$ ensure the continuity of production with all elements of the system,

- guarantee the implementation of production plans.

Some enterprises try to configure their production systems by developing their own technologies and innovative product assumptions. These solutions are usually based on modern platforms - therefore, they are supported by integrated ERP (Enterprise Resource Planning) systems, which eliminate unreliable and defective elements of the planning chain $[11,12,13]$. 


\section{Methodology and research}

The analysis of selected models of machining sets (automation rate) was based on a set of logistic assumptions concerning production in selected integrated systems. The most popular systems on the Polish market with the most advanced technological functions for the production of beds were selected for the analysis. The process was parameterised with the assumption to use the working time for the assumed production load of machines and devices at $85 \%$ (Table 1). The dimension and quality requirements concerning wood, which is the most common material, were used for full analysis of the available requirements that products can meet as well as the limitations encountered during processing. The technical specification in this study was based on the requirements concerning the production of solid and glued wooden elements. The use of selected elements is specified in the wooden frame construction programme. The general characterisation of the machine modules allowing for logistic flows in a selected production summary shows the basic technical requirements concerning integrated production systems.

It is noteworthy that all integrated IT supervision/control systems are similar to each other in terms of technology. The list of technological operations is adjusted to the general orientation of intended use of manufactured elements, and the programme takes the needs of individual types of production into account. The production programme and its adaptation to market needs is of fundamental importance for enterprises of various sizes and organisational structures. However, it is necessary to remember that if automation interferes too much with the production programme, which needs to be adapted to individual products, it often causes unsuccessful implementations. In order to evaluate the existing machinery systems the comparison of the evaluation criteria was generally simplified. The evaluation of differences according to the gradation of processing included the following subassemblies (Fig. 1):

- the raw material loading subassembly,

- the pre-treatment subassembly,

- the monitoring subassembly,

- the cutting optimisation subassembly,

- the subassembly for sorting and lengthwise joining of elements.

The automated loading subassembly collects the raw material (dry timber), destacks it while collecting spacers, and then queues, turns, and manipulates planks to align their faces. This stage is limited by the dimensions of the assortments, the dimensions of the stack and its weight. The parameters of additional material in the form of sawn timber with defects as well as the parameters of spacers are also important. The transport length of the conveyor and its feed speed in $\mathrm{m} / \mathrm{min}$ need to be taken into account for each component of the subassembly. Stacks can be transported to the destacker automatically or by the operator, who sends a signal after receiving the signal of readiness to accept the stack. It is noteworthy that the zone of the timber curvature orientation detector requires the insertion of a $180^{\circ}$ turntable with the axis directed to the timber length. At the very beginning of the process the requirements for the use of devices correcting and reducing the material flow are influenced by defects. This is achieved by the cross-cut section limited by the cross-cut length and the cutting speed. Only when the functions of preparatory and processing devices are combined in this way it is possible to ensure that the loading volume of the material supplied to the warehouse guarantees its further processing. The parameters defining the warehouse demand and the boundary dimensions of packages during the completion of production sets are components of the nominal dimensions of individual semi-finished products. The results of simulation of the warehouse demand translate into the planned areas of buffer storages (Table 2). 


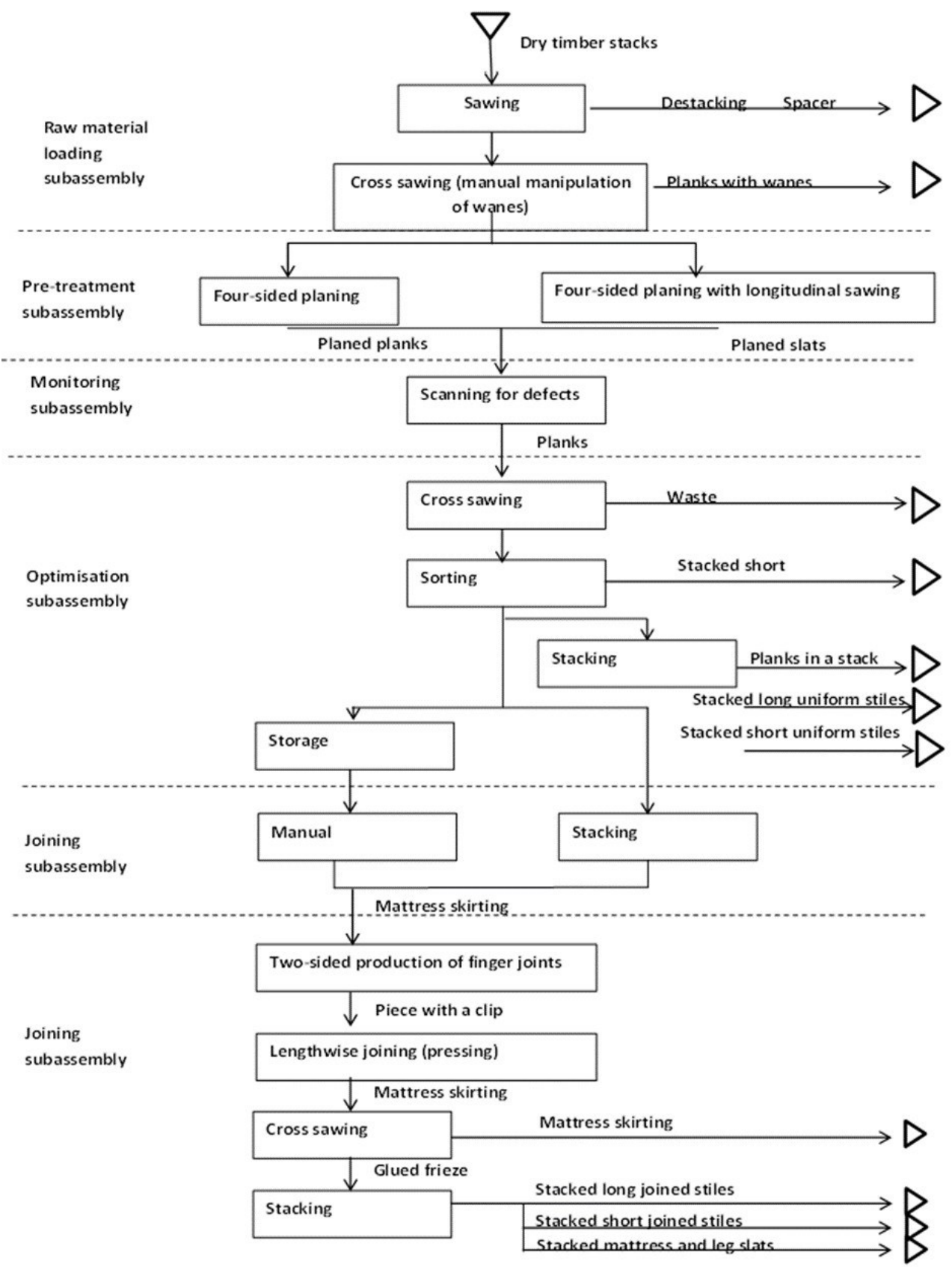

Fig. 1. The pinewood processing optimisation line in the production of solid and glued elements.

A storage with an accelerating device enables the automatic collection of an element when the accelerator zone is released and its longitudinal acceleration ranges from 0 to 250 $\mathrm{m} / \mathrm{min}$ to the next station, i.e. the planing machine. Another element influencing the qualitative processing of wood materials is the processing subassembly, which planes and bevels timber on four sides and optionally saws boards longitudinally into slats. 
In order to achieve full automation subassemblies with functional production assumptions compliant with the process requirements should be separated.

Rough machining is the basis for a proper qualitative analysis and optimisation of the cutting of elements by means of the monitoring subassembly (qualitative scanning of surfaces). This process involves the need to reduce the share of removed wood surface by 0.2-1 mm per side and obtain sufficient exposure of the qualitative features of the material in order to identify it and indicate the acceptable range of defects in the structure of elements for further processing. Planed elements are collected from the receiving buffer of the machining subassembly through the cross conveyor and transferred to the feeding system of the scanner. The scanner optically recognises defects and defines the automatic cutting plan. The following elements in the construction of this node are particularly important: the receiving buffer from the machining subassembly, the cross conveyor with the right speed and positioning accuracy, the automatic element feeding system and the scanner itself with a four-sided defect detection and identification system: knots and their location, wanes, cracks, blue stains, decay, resin stains, and dimensional deviations. The speed of longitudinal travel (100-150 mps), which limits the efficiency of optimised elements, is the disadvantage of these devices.

The optimisation subassembly is based on automatic lengthwise cutting according to the list of requirements concerning the use of elements. The creation of the length of elements is limited by the minimum length of edged pieces (elements for further processing). 150 $\mathrm{mm}$ is generally assumed as the boundary value due to the feed-and-saw support system. The process of elimination of unacceptable defects as well as the minimum and maximum edged piece length criteria translate into operational times and performance limitations. In order to meet the requirement of cutting performance limitations it may be necessary to use one or two optimisers (automatic cross-cut saws).

The process of separation of the number of length configurations of elements directly affects their automatic sorting. Meeting low quality requirements results in an increased share of full-length elements, which will not restrict subsequent working hubs. At the same time, it is necessary to formulate guidelines concerning automatic stacking into groups (short, long). In order to separate edged pieces in the most common range of 150-600 mm it is necessary to design and introduce the conveyor section with automatic transfer to the lengthwise-joining line and the option of redirection to the buffer storage.

The edged-piece joining subassembly is based on the assumption that edged pieces obtained at the cross-cutting optimisation stage enter the level cutting and profile milling (multi-wedge joint) zone. The double-sided profiling of front joints for wedge joints (furniture joints of 4-10 mm in length) in edged pieces is combined with the application of adhesive (in PVAC furniture joints). This operation requires the use of spray or comb nozzle systems. Edged pieces are joined lengthwise by being pressed against each other so that their profile parts are connected and the bonding of adhesive in an automatic press is initiated. This process increases the temperature of the adhesive system caused by highfrequency currents or the transfer of technological heat by the contact method. Next, the manufactured glued strips are cross-sawn to the required length (according to the specification). 
Table 1. Performance requirements for in-line operations.

\begin{tabular}{|c|c|c|c|c|c|c|c|c|c|}
\hline \multirow{3}{*}{ Type of elements } & \multicolumn{9}{|c|}{ Raw material optimization line } \\
\hline & 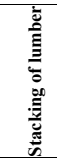 & 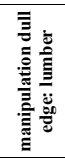 & 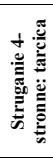 & \multirow[t]{2}{*}{ 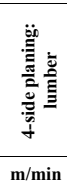 } & \multirow[t]{2}{*}{ 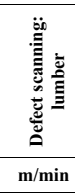 } & 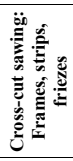 & 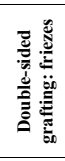 & 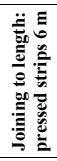 & 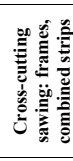 \\
\hline & & .../min & & & & \multicolumn{4}{|c|}{ pes../min } \\
\hline long piece ext.. & 2.14 & 1.9 & 1.9 & 11.6 & 11.6 & 19.7 & 16.4 & 0.8 & 2 \\
\hline long piece inside. & 0.43 & 0.4 & 0.4 & 4.6 & 9.2 & 16.1 & 13.1 & 0.7 & 2 \\
\hline mini inner element (solid) & 0.04 & 0.0 & 0.0 & 0.4 & 0.9 & 8.0 & 0 & 0 & 0 \\
\hline short piece outer (solid) & 0.43 & 0.4 & 0.4 & 4.7 & 4.7 & 4.0 & 0.0 & 0.0 & 0 \\
\hline short piece inside (solid) & 0.21 & 0.2 & 0.2 & 2.2 & 4.4 & 4.0 & 0.0 & 0.0 & 0 \\
\hline strip & 5.06 & 4.6 & 4.6 & 27.3 & 27.3 & 73.6 & 58.2 & 1.9 & 11 \\
\hline Coef. of expl. of working time & \multicolumn{9}{|c|}{$85 \%$} \\
\hline material output per long. & $100 \%$ & $90 \%$ & $97 \%$ & $97 \%$ & $86 \%$ & $93 \%$ & $99.5 \%$ & $95 \%$ & \\
\hline
\end{tabular}

Table 2. Scheduling a stock of items per shift.

\begin{tabular}{|c|c|c|c|c|c|c|c|c|c|c|c|c|c|c|c|}
\hline \multirow[b]{2}{*}{ Type of elements } & \multicolumn{10}{|c|}{ Single element pack } & \multicolumn{5}{|c|}{ Component storage } \\
\hline & 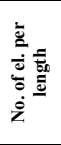 & 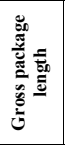 & 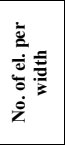 & 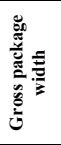 & 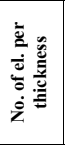 & 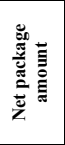 & 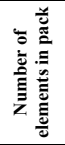 & 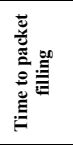 & 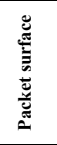 & 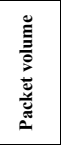 & 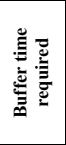 & 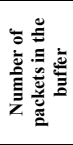 & 莺 & 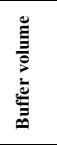 & 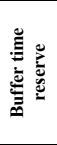 \\
\hline & pes. & $\mathbf{m m}$ & pes. & $\mathbf{m m}$ & pes. & mm & pes. & $\mathbf{h}$ & $\mathrm{m}^{2}$ & $\mathbf{m}^{3}$ & h & pes. & $\mathbf{m}^{2}$ & $\mathbf{m}^{3}$ & h \\
\hline long piece ext. & 1 & 2200 & 9 & 765 & 50 & 1000 & 450 & $0: 16$ & 1.7 & 1.7 & $4: 00$ & 14.7 & 24.8 & 24.8 & 28 \\
\hline long piece inside.. & 1 & 2200 & 15 & 795 & 50 & 1000 & 750 & $0: 10$ & 1.7 & 1.7 & $5: 00$ & 27.7 & 48.5 & 48.5 & 87 \\
\hline short piece outer (solid) & 1 & 1000 & 9 & 765 & 50 & 1000 & 450 & $0: 06$ & 0.8 & 0.8 & $4: 00$ & 36.7 & 28.1 & 28.1 & 69 \\
\hline short piece inside (solid)) & 1 & 1000 & 15 & 795 & 50 & 1000 & 750 & $0: 05$ & 0.8 & 0.8 & $3: 00$ & 34.7 & 27.6 & 27.6 & 108 \\
\hline strip & 1 & 1000 & 8 & 800 & 60 & 960 & 480 & 0:09 & 0.8 & 0.8 & $8: 00$ & 52.7 & 42.1 & 42.1 & 23 \\
\hline
\end{tabular}




\section{Discussion}

The use of machining modules enables precise adjustment of the throughput to the configured forms of raw material and adjustment of the desired efficiency of machining subassemblies to achieve the required quality, quantity and form of products. The adjustment of the parameters of machinery and auxiliary devices enables more efficient management of production processes. The administration of inter-operational warehouses facilitates the optimisation of material flows as well as full tracking of the completion of elements and their distribution to subsequent stations. The optimisation of the inventory function for one or more forms of elements enables the control and analysis of the warehouse stock. Each material can be assigned to a warehouse location and each location can determine the direction of processing. When the material is transferred to the warehouse, elements can be automatically fed in a series or batch to processing stations. The group of the highest value to the production order is issued first. Machining modules sets equipped with tool systems, which are the basis for making decisions controlling the rate of material flow, also need to be supported logistically to assess their wear. The tool requirements secure smooth implementation of production plans. The adjustment of requirements concerning the quality and dimensions of manufactured elements to the devices affects their individual efficiency. This also applies to poorly developed products (short elements of low quality) [14]. These functions of the production module support decisions about the selection of elements, including decisions about permissible defects and their location, by scanning individual items. This process affects the use of the processing and storage zone. The quality control function verifies the usefulness of materials coming from various sources. Finished products and stocks also enable more flexible production in the adopted technology.

The module described above presented examples of the most important functions for shaping the machine demand. Each company can adapt the functions of the machine park to its own requirements.

The increasing diversification in wood production results in an increased demand for precision machining equipment, which rationalises the costs and the rate of operation of the production line. In consequence, the independence of the enterprise also increases, because it can ensure that high quality products are manufactured with the appropriate technology, in a short time and at the best price.

In order to meet the changing conditions on the sales markets it is necessary to creatively solve problems of automated production and material flow logistics. Such farreaching automation of the main machining functions requires advanced and versatile IT systems, which set and control the fulfilment of functional specifications of manufactured products. Due to the specific nature and heterogeneity of wood it is necessary to continue research to extend the assessment of subjective control of wood processing with regard to the place of use of this material.

\section{Conclusions}

There are numerous variables affecting the methods of selection of wood processing machines and devices:

- individual and non-equivalent treatment of raw wood quality criteria,

- the separation of functional criteria in the processing of timber made from various wood species, 
- using preferences concerning the standardisation and grouping of production criteria, determining the scale of production, etc.,

- objective assessment of the right selection of working teams according to the processing criteria or standardised assessment,

- compliance with the cost conditions, which depends on the size of the enterprise and its economic potential,

- defined indications concerning the level of automation and optimisation of the machinery-assisted manufacturing process (depending on the assumed quality criteria and preferences).

When selecting processing systems, a weighting system should be used to indicate the elements (quality, dimensions or performance) that are of paramount importance for a specific production situation. Parameterization is indicated as a dimensional and qualitative function that has a significant impact on the industrial production of furniture. Thanks to this, the results of machinery investments in individual machining categories will correspond to the evaluation criteria expressed in the form of an economic calculation. The problem discussed in this article is a combination of real categories of qualitative and dimensional diversity concerning raw materials, manufactured products and estimated costs of automation investments in an enterprise.

Research conducted under the project POIR 01.01.01-00-802/19/ 'The Development of an Original Technological Process Resulting in Higher Productivity, Efficiency and Quality of Wood Products'

\section{References}

1. L. Zawadzka, J. Badurek, (Red. L. Zawadzka). Gdańsk: Wydawnictwo Politechniki Gdańskiej, s. 19-23. (2004)

2. J. Badurek, Współczesne problemy i modelowanie systemów gospodarczych. (Red. L. Zawadzka). Gdańsk. Wydawnictwo Politechniki Gdańskiej (2006)

3. K. Rutkowski, praca zbiorowa, Difin Warszawa, 85-86. (2001)

4. J. Coyle, E. Bardi, C.J. Langley, PWE Warszawa, 155. (2002)

5. Łęgowik-Świącik S., Stępień M., „Logistyka”, nr 6. (2016)

6. M. Brzeziński, Placet, Warszawa, (2002)

7. S. Dolny, J. Strumiński, Akademia Rolnicza, Poznań, 1993.

8. S. Owczarski, Tendencje rozwojowe logistyki, Wydawnictwo Naukowe Wyższej Szkoły Kupieckiej, Łódź (2006)

9. Cz. Skowronek, Z. Sarjusz-Wolski, wyd. IV zm., PWE, Warszawa 2008.

10. H.C., Martínez León, J. Calvo-Amodio, J. Clean.Prod. 142(4), 4384-4402 (2017). https://doi.org/10.1016/j.jclepro.2016.11.132.

11. M.J. Gil-Molt ' o, D. Varvarigos, Resource and Energy Economics 35, 486 - 504. (2013).

12. A. Sengupta, J. Environ. Econ. Manag. 71, 125 - 141. (201)

13. L. Zhang, , J. Wang, , J. You, Eur. J. Oper. Res. 241, 63 - 73. (2015)

14. M. Jagodziñski, Bielsko Biaïa: WSI i Z. (2020) 